\title{
The effects of NMDA receptor antagonists on attentional set-shifting task performance in mice
}

\author{
Tomasz Kos • Agnieszka Nikiforuk • Dominik Rafa • \\ Piotr Popik
}

Received: 29 April 2010 /Accepted: 11 November 2010 / Published online: 16 December 2010

(C) The Author(s) 2010. This article is published with open access at Springerlink.com.

\begin{abstract}
Rationale and objectives Cognitive deficits, including an impaired ability to shift perceptual attentional set, belong to the core features of schizophrenia, are associated with prefrontal cortical dysfunctions, and may involve glutamate NMDA receptors. Although phencyclidine disturbs cognitive flexibility, little is known about the effects of ketamine and other NMDA antagonists that differ in receptor subunit selectivity, particularly in the mouse species.

Methods At different times following the administration of ketamine, the NMDA NR2B-subtype specific antagonist Ro 25-6981, or the atypical antipsychotic sertindole, male $\mathrm{C} 57 \mathrm{Bl} / 6 \mathrm{~J}$ mice were investigated in a modified version of attentional set-shifting task (ASST).

Results Specific extra-dimensional shift (EDS) deficit was observed in all control mice. As revealed by the increased number of trials, time and errors to reach criterion, ketamine at 10 or $20 \mathrm{mg} / \mathrm{kg}$ given $50 \mathrm{~min}$ prior to sessions, but not at $10 \mathrm{mg} / \mathrm{kg}$ given 3 or $24 \mathrm{~h}$ prior to sessions, further worsened the EDS performance. Sertindole $(2.5 \mathrm{mg} / \mathrm{kg})$ prevented ketamine-induced cognitive inflexibility, although it did not affect ASST performance when given alone. In contrast to ketamine, Ro $25-6981$ at 10 but not $3 \mathrm{mg} / \mathrm{kg}$, reduced the number of trials and errors to criterion, suggesting
\end{abstract}

\footnotetext{
T. Kos $\cdot$ A. Nikiforuk $\cdot$ D. Rafa $\cdot$ P. Popik $(\bowtie)$

Behavioral Neuroscience, Institute of Pharmacology,

Polish Academy of Sciences,

12 Smętna Street,

31-343, Kraków, Poland

e-mail: nfpopik@cyf-kr.edu.pl

P. Popik

Faculty of Public Health, Collegium Medicum,

Jagiellonian University,

Kraków, Poland
}

a facilitation of cognitive flexibility. Finally, as revealed by the number of trials and time to criterion measures, Ro 25-6981 $(10 \mathrm{mg} / \mathrm{kg})$ administration to ketamine $(10 \mathrm{mg} / \mathrm{kg})$-pretreated mice inhibited ketamine-induced cognitive inflexibility.

Conclusion The present study provides an improved and reliable mouse ASST protocol and confirms and extends previous findings demonstrating that NR2B subunitselective antagonists improve cognitive processes.

Keywords Ketamine - NMDA receptor antagonist . NR2B-selective antagonist - Mouse - Cognition .

Schizophrenia $\cdot$ Animal model

\section{Introduction}

Schizophrenia is characterized by well-known "positive" and "negative" symptoms and by less recognized cognitive deficits in executive functions, working memory, and attention (Bowie and Harvey 2006). These cognitive deficits are present at the onset of illness, persist without remission throughout most of patients' lives, and may precede the development of "positive" symptoms (Brewer et al. 2006). Flexibility in response to a change in attentional set toward stimuli is controlled by the prefrontal cortex (PFC) and is commonly assessed in patients using the Wisconsin Card Sorting Test (WCST; Grant and Berg 1948; Elliott et al. 1998). A poor WCST performance is observed not only in schizophrenics but also in patients with frontal lobe damage (Pantelis et al. 1999).

The impairments in executive functions observed in WCST in humans can be investigated using a rodent version of the attentional set-shifting task (ASST) developed by Birrell and Brown (2000). The ASST requires animals to initially learn a rule and form "an attentional set" 
within the same stimulus dimension, by discriminating between, e.g., the odors associated with food reward. During the extra-dimensional (ED) shift, the crucial and most difficult part of the test, the subjects have to rapidly switch their attention to a new and previously irrelevant stimulus dimension and to discriminate between, e.g., the media covering the food reward. Although an increasing number of laboratories have successfully used the ASST in rats, most of the attempts to adapt this procedure for use in mice have failed to demonstrate an ED shift deficit (Colacicco et al. 2002; Laurent and Podhorna 2004; Zhuo et al. 2007; Levi et al. 2008). Only one procedure, described by Garner et al. (2006) and replicated with slight modification by Papaleo et al. (2008), has shown a significant extra-dimensional shift (EDS) phase deficit in this species. However, our laboratory was unable to demonstrate an ED shift impairment even with these modifications, and therefore, the first goal of the present study was to establish the conditions allowing for the measurement of reliable set-shifting in mice.

Converging lines of evidence indicate the involvement of glutamate NMDA transmission in schizophrenia. A single dose of an NMDA receptor antagonist, such as phencyclidine (PCP) or ketamine, induces symptoms of acute psychosis in healthy volunteers (Luby 1959; Javitt and Zukin 1991). Because these symptoms are indistinguishable from some symptoms of schizophrenia (Krystal et al. 1994), antagonists of NMDA receptors are routinely used in preclinical research as a pharmacological model of this psychosis (Olney and Farber 1995; Jentsch and Roth 1999). The acute administration of ketamine impairs attentional set-shifting as measured by the WCST in healthy humans (Krystal et al. 2000) and in the rat (Nikiforuk et al. 2010). Therefore, the second goal of the present study was to investigate the ketamine-induced impairment of ASST in mice.

Compared to conventional antipsychotics, relatively novel atypical compounds, such as sertindole, display an advantageous profile of pro-cognitive actions in schizophrenia. A recent multi-center, randomized, double-blinded clinical trial indicated a beneficial effect of sertindole on executive functions in patients with schizophrenia (Gallhofer et al. 2007); this medication also reduced the debilitating effects of ketamine in the Stroop task in healthy volunteers (Vollenweider et al. 1999). Several preclinical studies have shown that sertindole reduces or reverses the impairing effects of subchronic PCP treatment (Rodefer et al. 2008; Broberg et al. 2009; Goetghebeur and Dias 2009) and of an acute dose of ketamine (Nikiforuk et al. 2010) in the rat ASST. An obligatory step in the validation of a given procedure relies on the demonstration of a positive effect of the medication previously found to be effective in similar conditions. The third goal of the present study was to investigate whether sertindole could reverse ketamineinduced deficits in the mouse version of the ASST.

NMDA receptors are heteromers composed of an obligatory NR1 (mouse zeta 1) subunit and of at least one type of the NR2 (NR2A-NR2D; mouse epsilon 1-4) subunits (Laube et al. 1998; Schorge and Colquhoun 2003). The type of NR2 subunit constituting the NMDA receptor affects its physiological and pharmacological properties (Monaghan and Larsen 1997; Loftis and Janowsky 2003). In addition, the brain distribution of NR2 subunits is not uniform (Monyer et al. 1994; Wenzel et al. 1995); although NR2A messenger RNA (mRNA) is distributed particularly in the cerebral cortex, hippocampus, and cerebellum, the NR2B transcript is selectively present in the forebrain with a high level of expression in the cerebral cortex, hippocampus, septum, caudate-putamen, and olfactory bulb. The NR2C mRNA is expressed predominantly in the cerebellum, and the NR2D transcript is detected in the thalamus, brain stem, and olfactory bulb. The NR2C and NR2D transcripts are found in a subset of hippocampal neurons, which are most likely interneurons (Ozawa et al. 1998).

This pattern of distribution suggests that subunit-specific NMDA antagonists may have differential effects under various physiological and pathological conditions (Skolnick et al. 2009). Although ketamine is regarded as an NR2-unspecific antagonist (Dravid et al. 2007), recent data indicate that it mainly affects NR1/2C and NR1/2D NMDA receptors (Kotermanski and Johnson 2009). Due to its antagonistic action at hippocampal NMDA receptors, ketamine may cause cortical disinhibition, which is relevant to some symptoms of schizophrenia, including cognitive inflexibility (Greene 2001; Homayoun and Moghaddam 2007; Lisman et al. 2008). In contrast, the NR2B-selective antagonist, CP-101,606 (traxoprodil), under certain test conditions, improves cognitive flexibility as assessed by the five-choice serial reaction time task (5-CSRT; Higgins et al. 2005). Therefore, the fourth goal of the present study was to investigate the effects of an NR2B-selective antagonist alone and in combination with ketamine in the ASST procedure. We used the Ro 25-6981 compound [(aR,bS)-a-(4-hydroxyphenyl)-b-methyl-4-(phenylmethyl)-1-piperidinepropanol hydrochloride] that is characterized by a $>5,000$-fold selectivity for NR2C/NR2B over NR2C/NR2A subunits of the NMDA receptor, usedependent binding properties and neuroprotective effects against glutamate toxicity (Fischer et al. 1997).

\section{Materials and methods}

Ethics

The experiments were conducted in accordance with the NIH Guide for the Care and Use of Laboratory Animals 
Table 1 Pairs of different stimuli used in the mouse version of the ASST

\begin{tabular}{lllll}
\hline Dimension & Exemplar pairs & & & \\
\hline Odor & Orange & Lemon & Spicy & Cream \\
& Arrack & Almond & Vanilla & Rum \\
\multirow{2}{*}{ Medium } & Fine gravel & Crumpled tissue & Cardboard & Bamboo sticks \\
& Beads & Aluminum balls & Plastic & Polystyrene \\
\hline
\end{tabular}

and were approved by the Ethics Committee for Animal Experiments, Institute of Pharmacology.

\section{Animals}

The studies were performed on male $\mathrm{C} 57 \mathrm{Bl} / 6 \mathrm{~J}$ mice (Institute of Pharmacology breeding facility, originating from the Jackson Laboratories and purchased from CharlesRiver, Germany) weighing approximately $24 \mathrm{~g}$ and being approximately 7 to 8 weeks old at the start of the experiment. The mice were housed in standard laboratory cages under standard colony $\mathrm{A} / \mathrm{C}$-controlled conditions: room temperature of $21 \pm 2^{\circ} \mathrm{C}$, humidity of $40 \%$ to $50 \%$, and a 12-h light/dark cycle (lights on at 06:00). The mice were individually housed and mildly food deprived (2.9 $\mathrm{g}$ of food pellets per day), with ad libitum access to water for 1 week prior to testing. Mice were food restricted throughout the experiment to maintain approximately $85 \%$ of their initially body weight. Behavioral testing was performed during the light phase of the light/dark cycle. Different groups of animals were used in different drug experiments.

\section{Attentional set-shifting task procedure}

The experiments were performed according to the procedure for mice described by Garner et al. (2006) and Papaleo et al. (2008) with some modifications. The mice were tested in a black acrylic U-shaped maze apparatus $(W \times L, 39 \times$ $39 \mathrm{~cm}$ ) with a wire grid floor. The starting compartment provided an entrance via guillotine doors into two identical testing compartments. A bowl with water was placed in the starting compartment to allow mice free access to water throughout the whole training procedure. The food reward (1/8 of Honey Nut Cheerio, Nestle $\left.{ }^{\circledR}\right)$ was presented in containers (glass dishes, $5 \mathrm{~cm}$ in diameter, $3 \mathrm{~cm}$ in depth). The containers were defined by a pair of cues with two stimulus dimensions: different kinds of digging media and distinct odors ( $2 \mu \mathrm{l}$ of a flavoring essence, Dr. Oetker ${ }^{\circledR}$, Poland, on a piece of the blotting paper fixed to the external wall of a glass dish prior to use). Different containers were used for each combination of the digging medium and odor. Stimulus dimensions are shown in Table 1.

The entire study consisted of several experiments. Each experiment was performed on three consecutive days with training sessions 1 and 2 on the 2 nd and 3rd days (Table 2).
Habituation (day 1)

On the first day of testing, mice were habituated to the apparatus, containers, and food reward for $5 \mathrm{~min}$. The four phases of shaping were then initiated; the first three phases with two trials each and the fourth phase with three trials were performed sequentially. During each trial, the mouse was placed in the starting compartment, and the guillotine door was raised to allow entry to the test compartment with the containers filled with the food reward. During the first phase, the food reward was placed at the bottom of an empty container. For the next phase, the containers were filled with $0.5 \mathrm{~cm}$ of wood shavings, and the food reward was placed on top of the filling. In the third phase, the reward was placed under a thin layer of wood shavings. In the final phase, the food reward was buried under $2 \mathrm{~cm}$ of wood shavings. Once the mice retrieved the food reward, they were allowed to consume it before being returned to the starting compartment.

\section{Session 1 (2nd day) and session 2 (3rd day)}

Each mouse was trained to discriminate between pairs of containers that differed in odor and/or the media covering the food reward. This training was performed during two sessions, which consisted of several phases with several trials. During each trial, the animal was placed in the starting compartment, and the guillotine door was raised to give the mouse access to two containers, only one of which contained the food reward. The food reward was buried under the surface of distinct digging media. The first three trials of each session were "free", meaning that even after an incorrect choice, the door remained open, and the mouse was allowed to investigate and collect the food reward from the opposite container. On subsequent trials, the door was closed upon the animal's entry to the compartment. If the mouse started to dig in the un-baited container (i.e., the container without the food reward), an error was recorded, the trial was terminated, and the mouse was returned to the starting compartment. Each mouse had to reach a criterion of eight correct discriminations out of ten consecutive trials to complete each phase. The inter-trial interval was approximately $5 \mathrm{~s}$, and the interval between consecutive phases in a given session was approximately $45 \mathrm{~s}$.

We followed the protocol of Papaleo et al. (2008) by inserting additional phases (IDS2 and IDSR2). However, in 
Table 2 Detailed illustration of the present ASST procedure

\begin{tabular}{|c|c|c|c|c|c|}
\hline Phase & Dimension & \multicolumn{2}{|l|}{ Discrimination 1} & \multicolumn{2}{|l|}{ Discrimination 2} \\
\hline \multicolumn{6}{|c|}{ Session 1} \\
\hline SD & Media & \multicolumn{4}{|c|}{ Fine gravel vs. beads } \\
\hline \multirow[t]{2}{*}{ CD } & \multirow[t]{2}{*}{ Media } & Orange & Arrack & Orange & Arrack \\
\hline & & Fine gravel & Beads & Beads & Fine gravel \\
\hline \multirow[t]{2}{*}{ CDR } & \multirow[t]{2}{*}{ Media } & Orange & Arrack & Orange & Arrack \\
\hline & & Fine gravel & Beads & Beads & Fine gravel \\
\hline \multirow[t]{2}{*}{ IDS } & \multirow[t]{2}{*}{ Media } & Lemon & Almond & Lemon & Almond \\
\hline & & Crumpled tissue & Aluminum balls & Aluminum balls & Crumpled tissue \\
\hline \multirow[t]{2}{*}{ IDSR } & \multirow[t]{2}{*}{ Media } & Lemon & Almond & Lemon & Almond \\
\hline & & Crumpled tissue & Aluminum balls & Aluminum balls & Crumpled tissue \\
\hline \multicolumn{6}{|c|}{ Session 2} \\
\hline \multirow[t]{2}{*}{ IDS2 } & \multirow[t]{2}{*}{ Media } & Spicy & Vanilla & Spicy & Vanilla \\
\hline & & Cardboard & Plastic & Plastic & Cardboard \\
\hline \multirow[t]{2}{*}{ IDSR2 } & \multirow[t]{2}{*}{ Media } & Spicy & Vanilla & Spicy & Vanilla \\
\hline & & Cardboard & Plastic & Plastic & Cardboard \\
\hline \multirow[t]{2}{*}{ EDS } & \multirow[t]{2}{*}{ Odors } & Cream & Rum & Cream & Rum \\
\hline & & Bamboo sticks & Polystyrene & Polystyrene & Bamboo sticks \\
\hline \multirow[t]{2}{*}{ EDSR } & \multirow[t]{2}{*}{ Odors } & Cream & Rum & Cream & Rum \\
\hline & & Bamboo sticks & Polystyrene & Polystyrene & Bamboo sticks \\
\hline
\end{tabular}

For each trial, mice were presented with either discrimination 1 or 2 . In this example at the SD phase, all digging dishes had no odor, and the subjects had to choose the beads as the correct digging medium (in italics). Note that the stimuli are the same for CD and CDR, for IDS and IDR, and for EDS and EDSR

contrast to the protocols of Papaleo et al. (2008) and Garner et al. (2006), we divided the whole ASST procedure into two sessions. The reason for using a two-session procedure was that the mice appeared satiated when we attempted to complete all of the phases of testing in 1 day. Therefore, session 1 consisted of a warm-up habituation trial (identical to the last trial of the habituation session) and five phases: (1) simple discrimination (SD), (2) compound discrimination (CD), (3) compound discrimination reversal (CDR), (4) intra-dimensional shift (IDS), and (5) intra-dimensional shift reversal (IDSR). The overall testing time for one animal during this session was approximately 60 to $70 \mathrm{~min}$. Session 2 also consisted of a warm-up habituation trial and four phases: (1) intra-dimensional shift 2 (IDS2), (2) intradimensional shift reversal (IDSR2), (3) EDS, and (4) extradimensional shift reversal (EDSR). The overall testing time for one animal during this session was approximately 40 to $50 \mathrm{~min}$.
Thus, the mice were exposed to a series of increasingly difficult discriminations during which they discriminated within a dimension (the media covering the food reward) that was relevant from the SD phase until the EDS phase. At the EDS phase, the mouse had to start discriminating within a new stimulus dimension (odors), and the previously relevant dimension (media) became irrelevant. This schedule was used for all of the subjects and was based on preliminary results that demonstrated a tendency for better performance when the sequence of dimension change was from the media to odors (data not shown). An example of the entire task is shown in Table 2.

\section{Drugs}

Ketamine (10\% aqueous solution of $115.34 \mathrm{mg} / \mathrm{ml}$, Biowet, Poland) and Ro 25-6981 compound [(aR,bS)-a-(4-hydroxyphenyl)-b-methyl-4-(phenylmethyl)-1-piperidinepropanol 
Fig. 1 a-c Relationship between the time of ketamine administration and attentional set-shifting performance in mice. Ketamine $(10 \mathrm{mg} / \mathrm{kg})$ was administered $50 \mathrm{~min}$ and 3 or 24 h before both sessions. $N=$ 8 mice per treatment condition. Data are presented as the mean \pm SEM. Symbols: $* P<0.05$ vs. vehicle, ${ }^{\mathrm{i}} P<0.05$ vs. IDS2 phase, ${ }^{\mathbf{k}} P<0.05$ vs. ketamine $10 \mathrm{mg} / \mathrm{kg}$ group at $50 \mathrm{~min}$ (the standard ketamine treatment); Newman-Keuls post hoc test
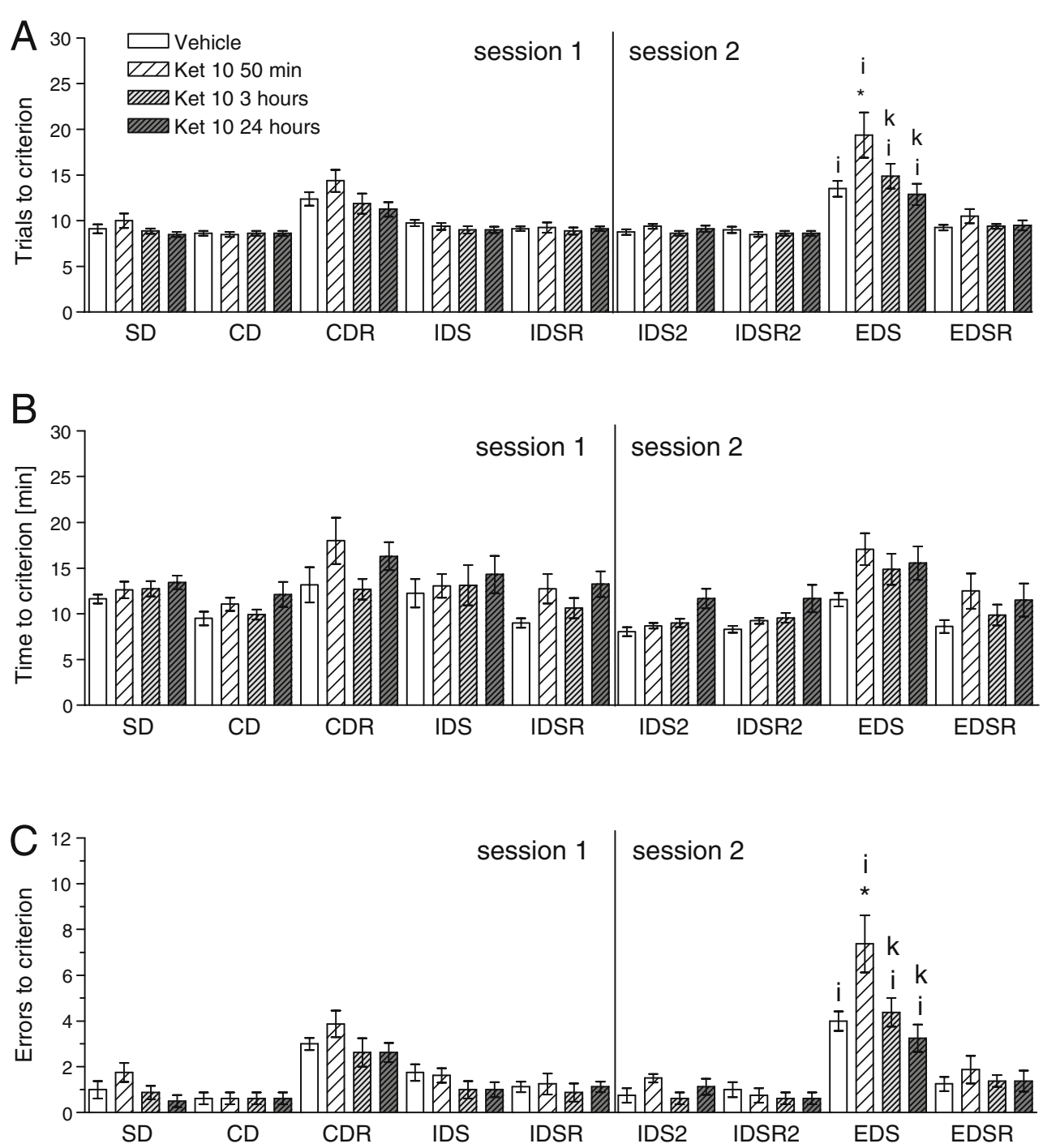

hydrochloride] (Sequoia, UK) were dissolved in distilled water. Sertindole (Sigma-Aldrich, Germany) was dissolved in a minimum amount of $0.1 \mathrm{M}$ hydrochloric acid and diluted with water. Drugs were administered before each of the two sessions. Therefore, the same animal received drug treatment twice: ketamine at $50 \mathrm{~min}, 3 \mathrm{~h}$ or $24 \mathrm{~h}$ (IP), the Ro 25-6981 compound at $30 \mathrm{~min}$ (IP), and sertindole at 120 min (PO). The ketamine "24-h" animals received the drug approximately $1 \mathrm{~h}$ after the last trial of habituation and approximately $1 \mathrm{~h}$ after session 1 . All of the compounds were administered in a volume of $10 \mathrm{ml} / \mathrm{kg}$, and the doses were chosen based on in-house data and published literature (Higgins et al. 2005; Rodefer et al. 2008).

\section{Statistics}

The following parameters were measured for each mouse: the number of trials to criterion, the number of errors to criterion, and the time to reach criterion, which was defined as eight correct choices out of ten consecutive trials. Statistical analyses were performed with Statistica 8.0 for Windows. The data from sessions 1 and 2 were calculated separately using repeated measures ANOVAs. Whenever significant interactions between the treatment conditions and the phase of a session were found, the data were analyzed with Newman-Keuls post hoc test; $P<0.05$ was deemed significant.

\section{Results}

Modification of the ASST procedure: general remarks

The modification of the protocols of Garner et al. (2006) and Papaleo et al. (2008) produced reliable set-shifting in mice because in all replications, the subjects required significantly more trials to reach the criterion during the EDS than during the IDS2 phase of the task. The 
Fig. 2 a-c Dose-dependent effects of ketamine on the attentional set-shifting task in mice. Ketamine (10 or $20 \mathrm{mg} /$ $\mathrm{kg}$ ) was administered $50 \mathrm{~min}$ before both sessions. $N=8-9$ mice per treatment. Data are presented as the mean \pm SEM. Symbols: ${ }^{*} P<0.05$ vs. vehicle, ${ }^{\mathrm{i}} P<0.05$ vs. IDS 2 phase, ${ }^{\mathbf{k}} P<0.05$ vs. ketamine $10 \mathrm{mg} / \mathrm{kg}$ group; Newman-Keuls post hoc test
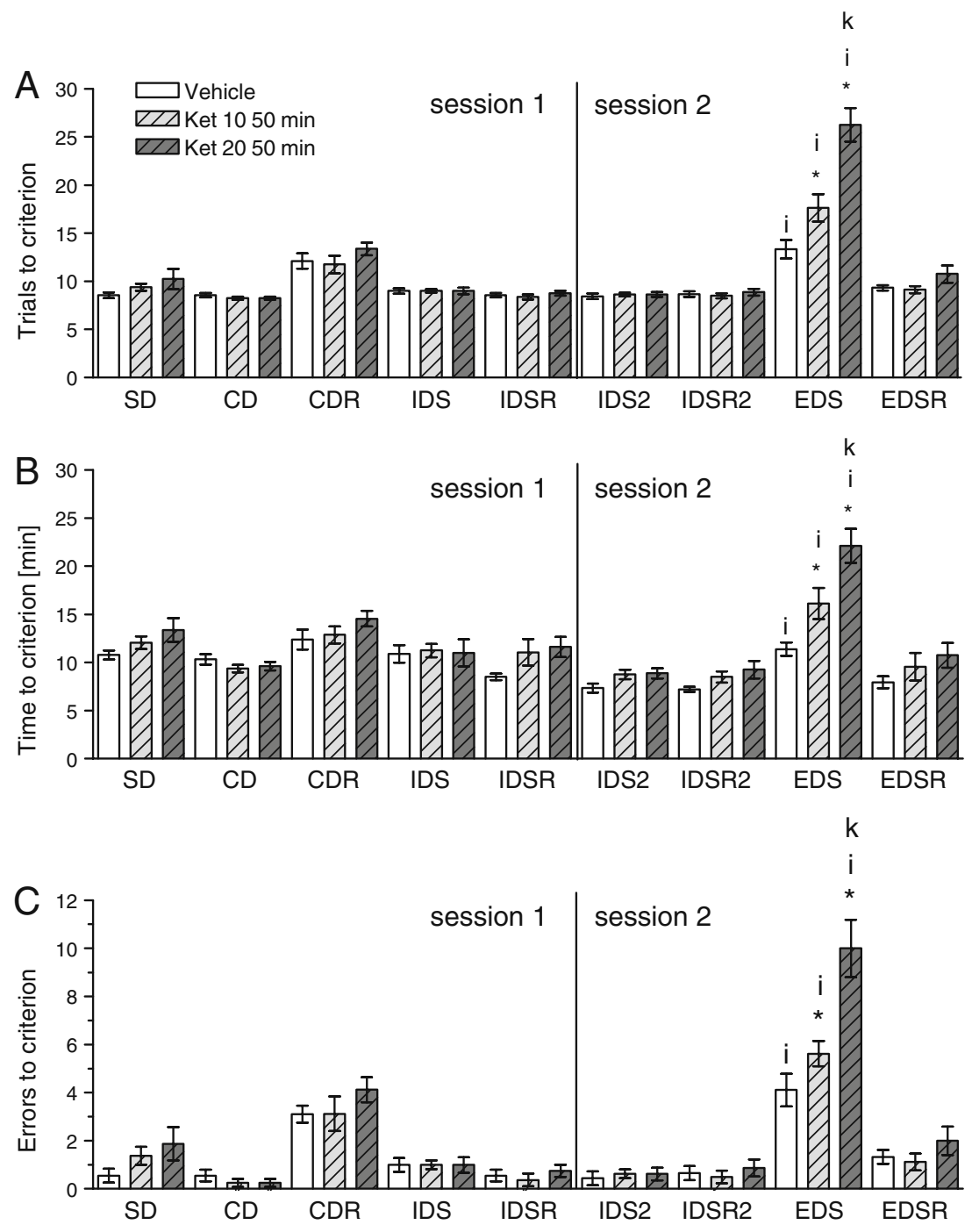

interaction factor between treatment conditions and the session phase for all of the experiments' session 1 measures, including trials, errors, and time to criterion, yielded insignificant results.

Time-related effects of ketamine on ASST performance

As assessed by the interaction factors between treatment condition and the phase of a given session, ketamine $(10 \mathrm{mg} / \mathrm{kg}, 3$ or $24 \mathrm{~h}$ before the test) changed neither the number of trials and errors nor the time to reach the criterion at any of the discrimination phases (Fig. 1a-c). In contrast, when administered $50 \mathrm{~min}$ before testing, ketamine significantly increased the number of trials $(F(9,84)=$ 2.72, $P<0.01$; Fig. 1a) and errors $(F(9,84)=2.86, P<0.01$; Fig. 1c) to criterion during the EDS phase. Although the time to criterion in this group was increased (Fig. 1b), the interaction (treatment $\times$ phase) for session 2 yielded insignificant results.
Dose-related effects of ketamine on ASST performance

Ketamine (10 and $20 \mathrm{mg} / \mathrm{kg}$, administered $50 \mathrm{~min}$ before the test) dose-dependently, significantly, and specifically increased the number of trials $(F(6,66)=17.49, P<0.001$; Fig. 2a), errors $(F(6,66)=8.22, P<0.001$; Fig. $2 \mathrm{~b})$, and the time to criterion $(F(6,66)=9.04, P<0.001$; Fig. $2 c)$ during the $\operatorname{EDS}$ phase. In all three measures, the effects of $20 \mathrm{mg} / \mathrm{kg}$ ketamine were significantly stronger than the effects of $10 \mathrm{mg} / \mathrm{kg}$.

Effects of sertindole on ketamine-induced deficits in the ASST

Similar to the two earlier experiments, $10 \mathrm{mg} / \mathrm{kg}$ of ketamine administered $50 \mathrm{~min}$ before the sessions increased both the number of trials $(F(3,84)=2.62, P<0.05$; Fig. 3a) and errors $(F(3,84)=2.67, P<0.05$; Fig. $3 c)$ to criterion during the EDS phase. Sertindole + ketamine treatment decreased these measures to the levels of the control group, and they were 
Fig. 3 Effects of sertindole on ketamine-induced deficits in the attentional set-shifting task in mice. Sertindole $(2.5 \mathrm{mg} / \mathrm{kg})$ and ketamine $(10 \mathrm{mg} / \mathrm{kg})$ were administered $2 \mathrm{~h}$ and $50 \mathrm{~min}$ before both sessions, respectively $(N=7-9$ mice per treatment). Data are presented as the mean \pm SEM. Symbols: * $P<0.05$ vs. vehicle, ${ }^{\mathrm{i}} P<0.05$ vs. IDS2 phase, ${ }^{\mathbf{k}} P<0.05$ vs. ketamine $10 \mathrm{mg} / \mathrm{kg}$ group; Newman-Keuls post hoc test
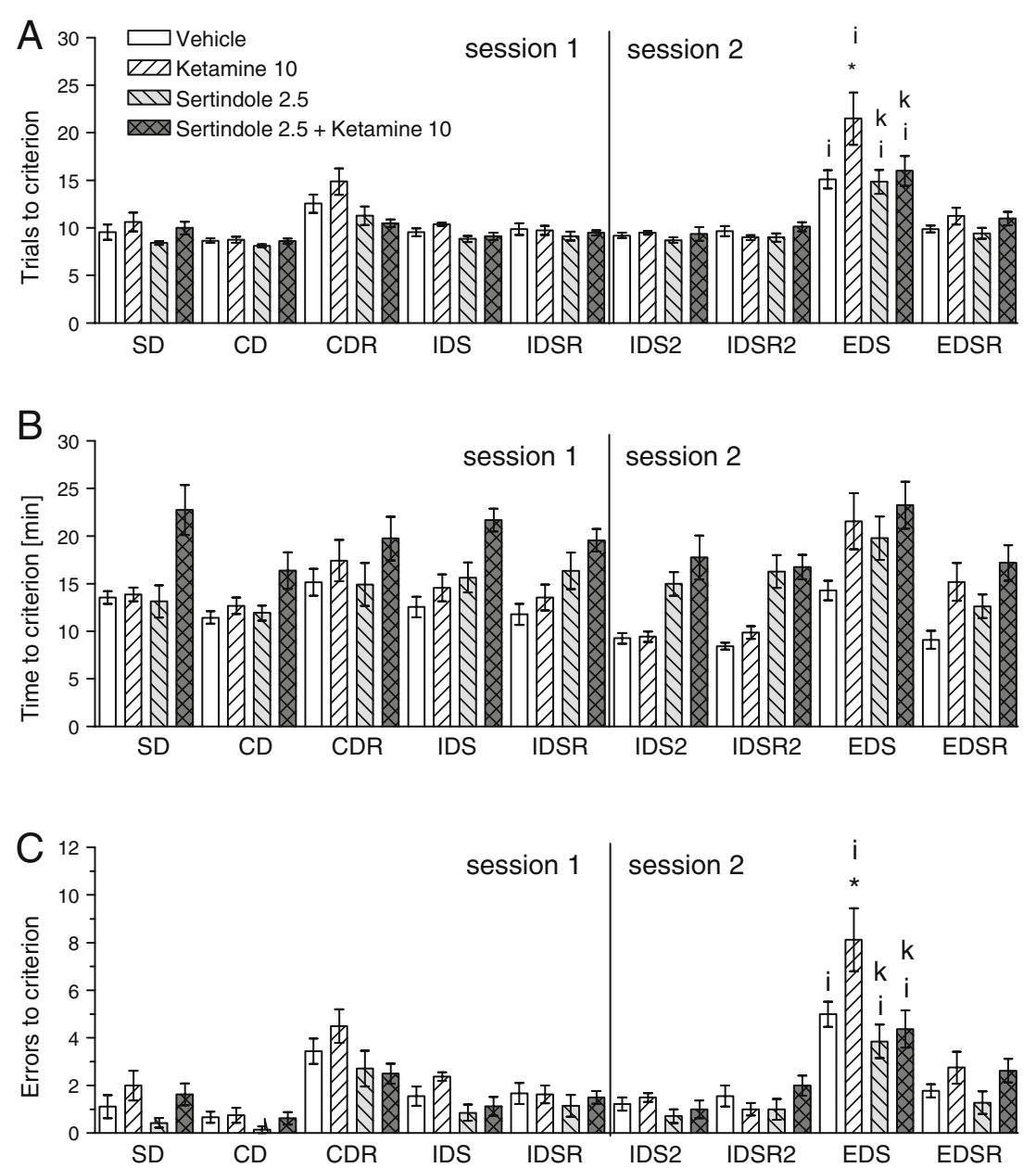

significantly lower compared to the ketamine alone treatment. Sertindole $(2.5 \mathrm{mg} / \mathrm{kg})$ did not change the number of trials or errors to criterion during the EDS phase compared with the vehicle-treated and sertindole + ketamine-treated groups (Fig. 3a, c). In this set of data, the time to criterion measure (Fig. 3b) was not affected by any of the treatments.

Dose-related effects of Ro 25-6981 on ASST performance

Ro 25-6981, administered $30 \mathrm{~min}$ before both sessions at $10 \mathrm{mg} / \mathrm{kg}$, but not at $3 \mathrm{mg} / \mathrm{kg}$, significantly and specifically facilitated performance during the EDS phase. The higher dose decreased the number of trials $(F(6,63)=4.97, P<0.001$; Fig. 4a) and errors $(F(6,63)=4.27, P<0.01$; Fig. $4 c)$ to criterion compared to the vehicle-treated group and compared to the group treated with the lower dose. The time to criterion measure (Fig. 4b) was not affected by these treatments.

Effects of Ro 25-6981 on ketamine-induced deficits in the ASST

Ketamine $(10 \mathrm{mg} / \mathrm{kg})$ increased the number of trials to criterion during the EDS phase, but the Ro 25-6981 treatment alone $(10 \mathrm{mg} / \mathrm{kg})$ decreased this measure compared to the vehicle-treated group $(F(3,84)=8.72, P<$ 0.001 ; Fig. 5a), confirming our earlier findings. The administration of Ro 25-6981 to ketamine-pretreated mice decreased the number of trials to criterion during the EDS phase compared to the vehicle- and ketamine-treated groups (Fig. 5a). A similar pattern of effects was observed for the errors to criterion measure; however, this statistical analysis yielded insignificant results $(P=0.10$; Fig. 5c). Ketamine $(10 \mathrm{mg} / \mathrm{kg})$ prolonged the time to criterion during the EDS phase (see also Fig. 2), and the ketamine + Ro 25-6981 treatment decreased this measure compared to the ketamine alone group $(F(3,84)=4.09, P<0.01$; Fig. $5 b)$. Similar to the earlier experiment, the Ro 25-6981 treatment shortened the time to criterion compared to the vehicle-treated group, but statistical analysis yielded insignificant differences.

\section{Discussion}

The present study demonstrated a procedure of attentional set-shifting in mice capable of revealing a deficit during the EDS phase, which was further impaired by ketamine 
Fig. 4 a-c Effects of Ro 256981 on attentional set-shifting task performance in mice. Ro $25-6981$ (3 or $10 \mathrm{mg} / \mathrm{kg}$ ) was administered $30 \mathrm{~min}$ before both sessions ( $N=8$ mice per treatment). Data are presented as the mean \pm SEM. Symbols: ${ }^{*} P<0.05$ vs. vehicle, ${ }^{\mathrm{i}} P<0.05$ vs. IDS 2 phase, ${ }^{\#} P<0.05$ vs. Ro 25-6981 at $3 \mathrm{mg} / \mathrm{kg}$; NewmanKeuls post hoc test
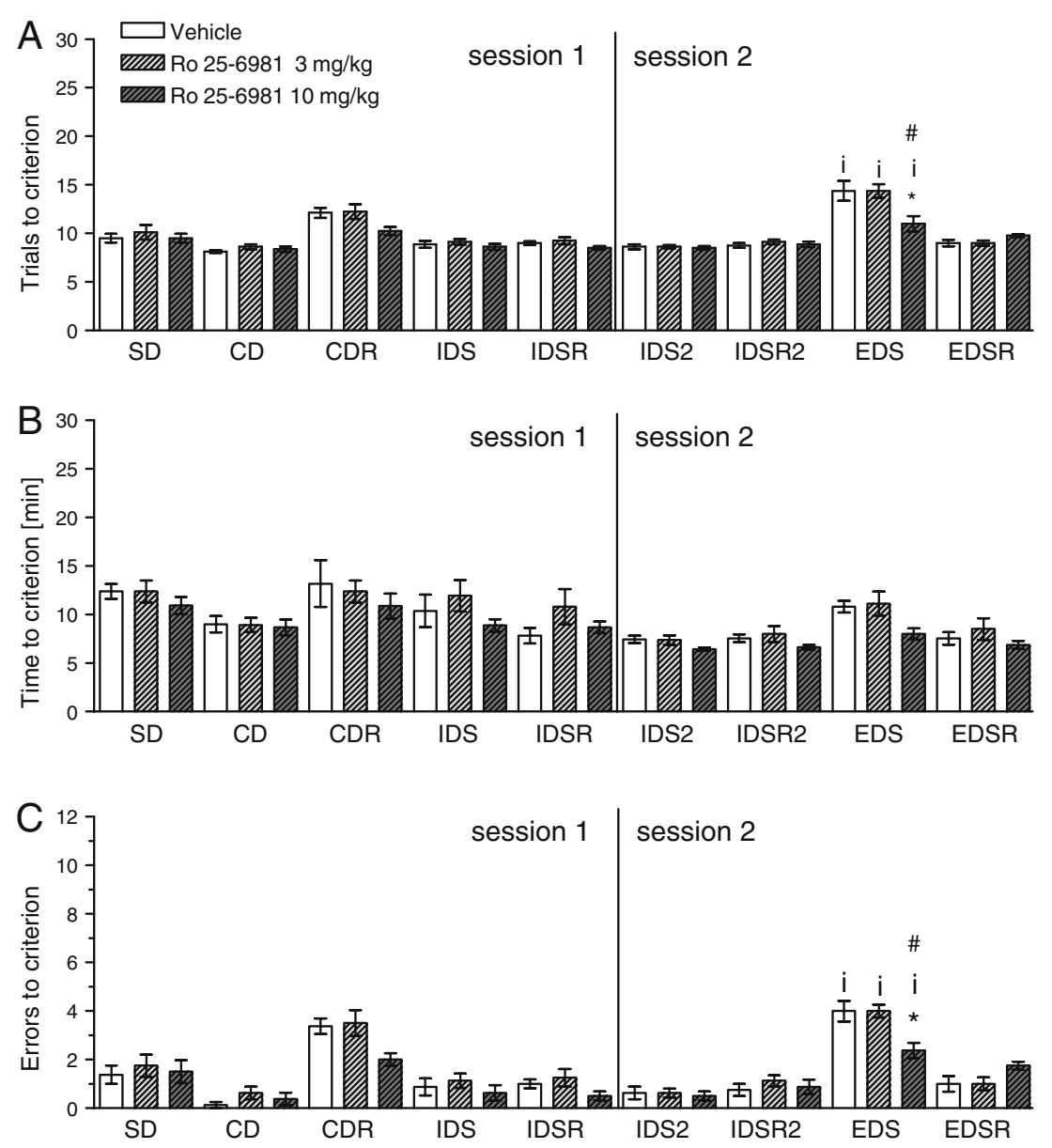

administration. We confirmed that the atypical antipsychotic sertindole alleviated ketamine-induced cognitive deficits. In addition, the present data suggest that the NR2B subunitselective NMDA antagonist Ro 25-6981 not only facilitated ASST performance during the EDS phase but also reversed ketamine-induced cognitive inflexibility.

Only two published modifications of the primary ASST procedure for rats (Birrell and Brown 2000) have successfully demonstrated significant EDS phase impairment in mice (Garner et al. 2006; Papaleo et al. 2008). Because mice were unable to complete the test in 1 day under our experimental conditions, we divided the procedure into two sessions and included additional phases (IDS2 and IDSR2). As pointed out by Garner et al. (2006), like reversal phases (CDR and IDSR), these additional phases serve to strengthen the cognitive set formation. This outcome was manifested by a general improvement in performance during the phases ranging from CD to IDSR2 followed by a poorer EDS phase performance, which is regarded as the primary measure of set-shifting. Under these conditions, we demonstrated reliable set-shifting in mice because, in all replications (Figs. 1, 2, 3, 4, and 5), the subjects required significantly more trials to reach the criterion during the EDS phase than during the IDS2 phase of the task. A drawback of the 2-day protocol is that the investigated compound has to be administered twice, but the relatively short duration of the test session could be considered as a potential advantage for the investigation of compounds characterized by a short half-life.

The present work confirms the results of Nikiforuk et al. (2010) demonstrating that, in the rat ASST, ketamine produces specific deficits in cognitive flexibility after a single dose given $50 \mathrm{~min}$ before the test and extends these findings to the mouse species. Although these studies cannot be compared directly, the observed effect was dose dependent; the higher dose of ketamine $(20 \mathrm{mg} / \mathrm{kg})$ more severely impaired the task performance compared to the lower dose $(10 \mathrm{mg} / \mathrm{kg})$. It was also time dependent; the ED shift deficit was demonstrated at $50 \mathrm{~min}$, but not 3 or $24 \mathrm{~h}$, following drug administration. The latter observation somewhat contrasts with the findings of Egerton et al. (2005), demonstrating that a single dose of PCP tested $24 \mathrm{~h}$ after administration produced an ED shift impairment. However, different NMDA receptor antagonists were used, and the studies were performed in a different species. Notably, in clinical experiments, WCST impairment is observed $40 \mathrm{~min}$ after ketamine infusion (Krystal et al. 2000), and ketamine-induced psychotomimetic effects, as 
Fig. 5 a-c Effects of Ro 256981 on ketamine-induced deficits in the attentional set-shifting task in mice. Ro 25-6981

$(10 \mathrm{mg} / \mathrm{kg})$ and ketamine $(10 \mathrm{mg} / \mathrm{kg})$ were administered 30 and $50 \mathrm{~min}$ before both sessions, respectively ( $N=8$ mice per treatment). Data are presented as the mean $\pm \mathrm{SEM}$. Symbols: ${ }^{*} P<0.05$ vs. vehicle, i $P<0.05$ vs. IDS 2 phase, ${ }^{\mathbf{k}} P<0.05$ vs. ketamine $10 \mathrm{mg} / \mathrm{kg}$ group; Newman-Keuls post hoc test
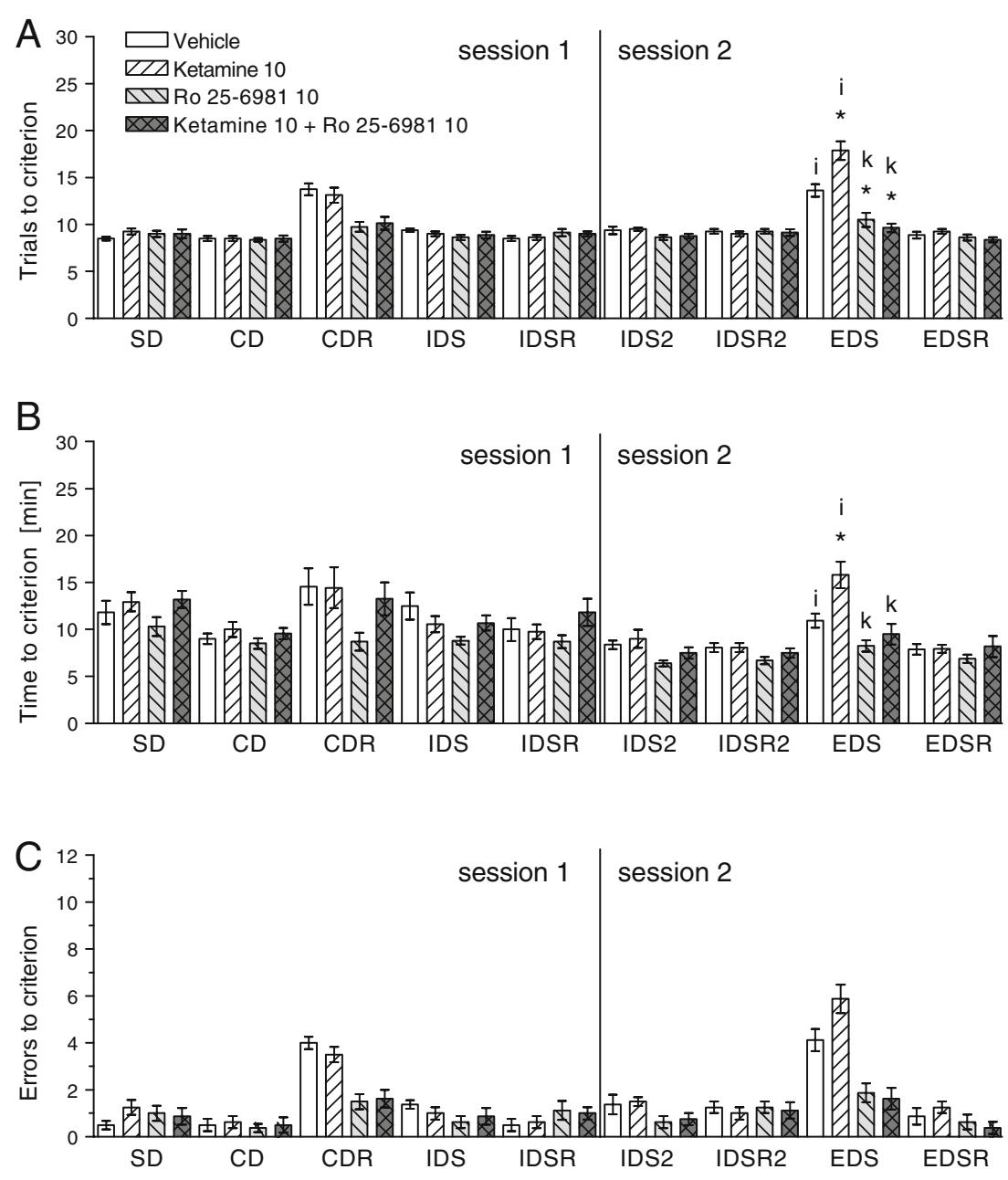

measured by the Brief Psychiatric Rating Scale, disappeared within $2 \mathrm{~h}$ after infusion (Berman et al. 2000; Zarate et al. 2006). Therefore, the current protocol appears to be a promising pharmacological tool for modeling mouse cognitive inflexibility. Its predictive validity is based on the inhibitory effects of sertindole (Fig. 3), which also reduced the impairing effects of PCP-like compounds in the rat ASST in former studies (Rodefer et al. 2008; Broberg et al. 2009; Goetghebeur and Dias 2009; Nikiforuk et al. 2010) and alleviated the cognitive impairments associated with schizophrenia (Gallhofer et al. 2007) and ketamine administration in healthy volunteers (Vollenweider et al. 1999).

The major finding of this set of experiments concerns the pro-cognitive effects of the NMDA NR2B subunit-selective antagonist Ro 25-6981 in the mouse ASST. These effects were shown by the reversal of the ketamine-induced cognitive deficit (Fig. 5) and by cognitive improvement in mice treated with Ro 25-6981 only (Fig. 4). The pro-cognitive effects of the NR2B-selective antagonist are in sharp contrast to the PCP-like antagonists, and to our knowledge, this is the first demonstration of an NMDA antagonist-induced procognitive action in the ASST. The effects of NR2B-selective antagonists on cognitive functions are complicated. The Ro 63-1908 does not affect performance in the Morris water maze and delayed matching to position task (DMTP) performance, though in 5-CSRT Ro 63-1908 produces an increase in premature responses, and in differential reinforcement of low-rate 24 s (DRL24) task, it reduces the interresponse time, suggesting an impairment of response inhibition (Higgins et al. 2003). Although traxoprodil does not affect spatial learning (Guscott et al. 2003), Ro 25-6981 disrupts spatial reversal learning and enhances perseveration in the Morris water maze (Duffy et al. 2008). Consistent with the latter report, NMDA $2 \mathrm{~B}$ subunit over-expression results in better performance in learning and memory tasks, like novel object recognition, the Morris water maze, and the t-maze, in mice (Tang et al. 1999; Cao et al. 2007) and rats (Wang et al. 2009).

Nonetheless, in tasks specifically assessing cognitive flexibility, like the 5-CSRT, both traxoprodil and Ro 25$6981(3-30 \mathrm{mg} / \mathrm{kg})$ increase premature responding and response speed with no error trade-off similar to Ro 631908. At a short inter-trial interval, Ro 63-1908 reliably improved performance, both in terms of response speed and 
accuracy, and traxoprodil improves accuracy and increases response speed in the DMTP task (Higgins et al. 2005). These authors conclude that selective NR2B NMDA antagonists promote impulsive-type responding that - under certain test conditions, such as a higher event rate of stimulus presentation-results in an improvement of task performance. Somewhat similar results have been reported by Gilmour et al. (2009), who show that NR2B-specific antagonists increase instrumental output in a series of variable interval schedules of reinforcement in an operant task. Our data appear to confirm these findings because the treatment with Ro 25-6981 not only reduced the number of trials to criterion (Fig. 4a) but also reduced, albeit insignificantly, the time required to complete the EDS phase of the set-shifting task (Figs. $4 \mathrm{~b}$ and $5 \mathrm{~b}$ ).

The present data cannot offer a convincing explanation of the mechanism for the pro-cognitive action of Ro 256981. The ASST does not allow for the measurement of all of the parameters that are typically recorded in 5-CSRT and is a relatively simple procedure with a remarkably lower workload. Nonetheless, we may speculate that the Ro 256981-induced reduction in the number of trials to criterion and in the time to complete the EDS phase resembles a similar improvement in performance (response speed and accuracy) as the improvements found in the 5-CSRT (Higgins et al. 2005). The ketamine-induced inhibition of hippocampal NMDA receptors may enhance the firing rate of glutamatergic PFC neurons and impair PFC-dependent functions, including cognitive flexibility (Greene 2001; Homayoun and Moghaddam 2007; Lisman et al. 2008). A high density of the NR2B subunit within the PFC, including infra-limbic regions (Wenzel et al. 1995), confirmed by autoradiography with [3H]-Ro 25-6981 (Mutel et al. 1998), suggests that the compound exerted its actions in the PFC. It is likely that the unique localization of the NR2B-containing NMDA receptors allows for the reversal of the ketamine-induced cognitive deficit in ASST via blockade of glutamatergic cortical disinhibition. Future studies will reveal the precise mechanism of the pro-cognitive action of this NR2B-selective NMDA antagonist.

\footnotetext{
Acknowledgments This study was supported by statutory activity funds from the Institute of Pharmacology, Polish Academy of Sciences (Kraków, Poland) and by the project UDA-POIG.01.03.0112-063/09-00 Prokog co-financed by the European Union from the European Fund of Regional Development (EFRD). The financial support of the Foundation for Polish Science to T. Kos is highly appreciated.
}

Open Access This article is distributed under the terms of the Creative Commons Attribution Noncommercial License which permits any noncommercial use, distribution, and reproduction in any medium, provided the original author(s) and source are credited.

\section{References}

Berman RM, Cappiello A, Anand A, Oren DA, Heninger GR, Charney DS, Krystal JH (2000) Antidepressant effects of ketamine in depressed patients. Biol Psychiatry 47:351-354

Birrell JM, Brown VJ (2000) Medial frontal cortex mediates perceptual attentional set shifting in the rat. J Neurosci 20:4320-4324

Bowie CR, Harvey PD (2006) Treatment of cognitive deficits in schizophrenia. Curr Opin Investig Drugs 7:608-613

Brewer WJ, Wood SJ, Phillips LJ, Francey SM, Pantelis C, Yung AR, Cornblatt B, McGorry PD (2006) Generalized and specific cognitive performance in clinical high-risk cohorts: a review highlighting potential vulnerability markers for psychosis. Schizophr Bull 32:538-555

Broberg BV, Glenthoj BY, Dias R, Larsen DB, Olsen CK (2009) Reversal of cognitive deficits by an ampakine (CX516) and sertindole in two animal models of schizophrenia - sub-chronic and early postnatal PCP treatment in attentional set-shifting. Psychopharmacol Berl 206:631-640

Cao X, Cui Z, Feng R, Tang YP, Qin Z, Mei B, Tsien JZ (2007) Maintenance of superior learning and memory function in NR2B transgenic mice during ageing. Eur J Neurosci 25:1815-1822

Colacicco G, Welzl H, Lipp HP, Wurbel H (2002) Attentional setshifting in mice: modification of a rat paradigm, and evidence for strain-dependent variation. Behav Brain Res 132:95-102

Dravid SM, Erreger K, Yuan H, Nicholson K, Le P, Lyuboslavsky P, Almonte A, Murray E, Mosely C, Barber J, French A, Balster R, Murray TF, Traynelis SF (2007) Subunit-specific mechanisms and proton sensitivity of NMDA receptor channel block. J Physiol 581:107-128

Duffy S, Labrie V, Roder JC (2008) D-serine augments NMDA-NR2B receptor-dependent hippocampal long-term depression and spatial reversal learning. Neuropsychopharmacology 33:1004-1018

Egerton A, Reid L, McKerchar CE, Morris BJ, Pratt JA (2005) Impairment in perceptual attentional set-shifting following PCP administration: a rodent model of set-shifting deficits in schizophrenia. Psychopharmacol Berl 179:77-84

Elliott R, McKenna PJ, Robbins TW, Sahakian BJ (1998) Specific neuropsychological deficits in schizophrenic patients with preserved intellectual function. Cogn Neuropsychiatry 3:45-70

Fischer G, Mutel V, Trube G, Malherbe P, Kew JN, Mohacsi E, Heitz MP, Kemp JA (1997) Ro 25-6981, a highly potent and selective blocker of N-methyl-D-aspartate receptors containing the NR2B subunit. Characterization in vitro. J Pharmacol Exp Ther 283:1285-1292

Gallhofer B, Jaanson P, Mittoux A, Tanghoj P, Lis S, Krieger S (2007) Course of recovery of cognitive impairment in patients with schizophrenia: a randomised double-blind study comparing sertindole and haloperidol. Pharmacopsychiatry 40:275-286

Garner JP, Thogerson CM, Wurbel H, Murray JD, Mench JA (2006) Animal neuropsychology: validation of the intra-dimensional extradimensional set shifting task for mice. Behav Brain Res 173:53-61

Gilmour G, Pioli EY, Dix SL, Smith JW, Conway MW, Jones WT, Loomis S, Mason R, Shahabi S, Tricklebank MD (2009) Diverse and often opposite behavioural effects of NMDA receptor antagonists in rats: implications for "NMDA antagonist modelling" of schizophrenia. Psychopharmacol Berl 205:203-216

Goetghebeur P, Dias R (2009) Comparison of haloperidol, risperidone, sertindole, and modafinil to reverse an attentional set-shifting impairment following subchronic PCP administration in the rata back translational study. Psychopharmacol Berl 202:287-293

Grant DA, Berg EA (1948) A behavioral analysis of degree of reinforcement and ease of shifting to new responses in a Weigltype card-sorting problem. J Exp Psychol 38:404-411 
Greene R (2001) Circuit analysis of NMDAR hypofunction in the hippocampus, in vitro, and psychosis of schizophrenia. Hippocampus 11:569-577

Guscott MR, Clarke HF, Murray F, Grimwood S, Bristow LJ, Hutson PH (2003) The effect of ( \pm )-CP-101, 606, an NMDA receptor NR2B subunit selective antagonist, in the Morris water maze. Eur J Pharmacol 476:193-199

Higgins GA, Ballard TM, Huwyler J, Kemp JA, Gill R (2003) Evaluation of the NR2B-selective NMDA receptor antagonist Ro 63-1908 on rodent behaviour: evidence for an involvement of NR2B NMDA receptors in response inhibition. Neuropharmacology 44:324-341

Higgins GA, Ballard TM, Enderlin M, Haman M, Kemp JA (2005) Evidence for improved performance in cognitive tasks following selective NR2B NMDA receptor antagonist pre-treatment in the rat. Psychopharmacol Berl 179:85-98

Homayoun H, Moghaddam B (2007) NMDA receptor hypofunction produces opposite effects on prefrontal cortex interneurons and pyramidal neurons. J Neurosci 27:11496-11500

Javitt DC, Zukin SR (1991) Recent advances in the phencyclidine model of schizophrenia. Am J Psychiatry 148:1301-1308

Jentsch JD, Roth RH (1999) The neuropsychopharmacology of phencyclidine: from NMDA receptor hypofunction to the dopamine hypothesis of schizophrenia. Neuropsychopharmacology 20:201-225

Kotermanski SE, Johnson JW (2009) Mg2+ imparts NMDA receptor subtype selectivity to the Alzheimer's drug memantine. J Neurosci 29:2774-2779

Krystal JH, Karper LP, Seibyl JP, Freeman GK, Delaney R, Bremner JD, Heninger GR, Bowers MB, Charney DS (1994) Subanesthetic effects of the noncompetitive NMDA antagonist, ketamine, in humans. Psychotomimetic, perceptual, cognitive, and neuroendocrine responses. Arch Gen Psychiatry 51:199-214

Krystal JH, Bennett A, Abisaab D, Belger A, Karper LP, Dsouza DC, Lipschitz D, Abidargham A, Charney DS (2000) Dissociation of ketamine effects on rule acquisition and rule implementation: possible relevance to NMDA receptor contributions to executive cognitive functions. Biol Psychiatry 47:137-143

Laube B, Kuhse J, Betz H (1998) Evidence for a tetrameric structure of recombinant NMDA receptors. J Neurosci 18:2954-2961

Laurent V, Podhorna J (2004) Subchronic phencyclidine treatment impairs performance of $\mathrm{C} 57 \mathrm{BL} / 6$ mice in the attentional setshifting task. Behav Pharmacol 15:141-148

Levi Y, Kofman O, Schwebel M, Shaldubina A (2008) Discrimination and avoidance learning in adult mice following developmental exposure to diisopropylfluorophosphate. Pharmacol Biochem Behav 88:438-445

Lisman JE, Coyle JT, Green RW, Javitt DC, Benes FM, Heckers S, Grace AA (2008) Circuit-based framework for understanding neurotransmitter and risk gene interactions in schizophrenia. Trends Neurosci 31:234-242

Loftis JM, Janowsky A (2003) The N-methyl-D-aspartate receptor subunit NR2B: localization, functional properties, regulation, and clinical implications. Pharmacol Ther 97:55-85

Luby ED (1959) Study of a new schizophrenomimetic drug-Sernyl. A M A Arch Neurol Psychiatry 81:363-369
Monaghan DT, Larsen H (1997) NR1 and NR2 subunit contributions to N-methyl-D-aspartate receptor channel blocker pharmacology. J Pharmacol Exp Ther 280:614-620

Monyer H, Burnashev N, Laurie DJ, Sakmann B, Seeburg PH (1994) Developmental and regional expression in the rat brain and functional properties of four NMDA receptors. Neuron 12:529-540

Mutel V, Buchy D, Klingelschmidt A, Messer J, Bleuel Z, Kemp JA, Richards JG (1998) In vitro binding properties in rat brain of [3H]Ro 25-6981, a potent and selective antagonist of NMDA receptors containing NR2B subunits. J Neurochem 70:2147-2155

Nikiforuk A, Golembiowska K, Popik P (2010) Mazindol attenuates ketamine-induced cognitive deficit in the attentional set shifting task in rats. Eur Neuropsychopharmacol 20:37-48

Olney JW, Farber NB (1995) NMDA antagonists as neurotherapeutic drugs, psychotogens, neurotoxins, and research tools for studying schizophrenia. Neuropsychopharmacology 13:335-345

Ozawa S, Kamiya H, Tsuzuki K (1998) Glutamate receptors in the mammalian central nervous system. Prog Neurobiol 54:581-618

Pantelis C, Barber FZ, Barnes TR, Nelson HE, Owen AM, Robbins TW (1999) Comparison of set-shifting ability in patients with chronic schizophrenia and frontal lobe damage. Schizophr Res 37:251-270

Papaleo F, Crawley JN, Song J, Lipska BK, Pickel J, Weinberger DR, Chen J (2008) Genetic dissection of the role of catechol- $O$ methyltransferase in cognition and stress reactivity in mice. $\mathrm{J}$ Neurosci 28:8709-8723

Rodefer JS, Nguyen TN, Karlsson JJ, Arnt J (2008) Reversal of subchronic PCP-induced deficits in attentional set shifting in rats by sertindole and a $5-\mathrm{HT}(6)$ receptor antagonist: comparison among antipsychotics. Neuropsychopharmacology 33:2657-2666

Schorge S, Colquhoun D (2003) Studies of NMDA receptor function and stoichiometry with truncated and tandem subunits. J Neurosci 23:1151-1158

Skolnick P, Popik P, Trullas R (2009) Glutamate-based antidepressants: 20 years on. Trends Pharmacol Sci 30:563-569

Tang YP, Shimizu E, Dube GR, Rampon C, Kerchner GA, Zhuo M, Liu GS, Tsien JZ (1999) Genetic enhancement of learning and memory in mice. Nature 401:63-69

Vollenweider FX, Bachle D, Umbricht D, Geyer M, Hell D (1999) Sertindole reduces S-ketamine induced attentional deficits in healthy volunteers. Biol Psychiatry 45:100S

Wang D, Cui Z, Zeng Q, Kuang H, Wang LP, Tsien JZ, Cao X (2009) Genetic enhancement of memory and long-term potentiation but not CA1 long-term depression in NR2B transgenic rats. PLoS ONE 4:e7486

Wenzel A, Scheurer L, Kunzi R, Fritschy JM, Mohler H, Benke D (1995) Distribution of NMDA receptor subunit proteins NR2A, $2 \mathrm{~B}, 2 \mathrm{C}$ and $2 \mathrm{D}$ in rat brain. NeuroReport 7:45-48

Zarate CA Jr, Singh JB, Carlson PJ, Brutsche NE, Ameli R, Luckenbaugh DA, Charney DS, Manji HK (2006) A randomized trial of an N-methyl-D-aspartate antagonist in treatment-resistant major depression. Arch Gen Psychiatry 63:856-864

Zhuo JM, Prescott SL, Murray ME, Zhang HY, Baxter MG, Nicolle MM (2007) Early discrimination reversal learning impairment and preserved spatial learning in a longitudinal study of Tg2576 APPsw mice. Neurobiol Aging 28:1248-1257 